OPEN ACCESS

Edited by:

Patricia Cogram,

Fraunhofer Research, Chile

Reviewed by:

Paulo Caramelli,

Universidade Federal de Minas

Gerais, Brazil

Gladys Elena Maestre,

University of Texas Rio Grande Valley,

United States

*Correspondence:

Nitton Custodio

ncustodio@ipn.pe

Andrea Slachevsky

andrea.slachevsky@uchile.cl

Received: 23 November 2016 Accepted: 23 June 2017 Published: 13 July 2017

Citation:

Custodio N, Wheelock A, Thumala D and Slachevsky A (2017) Dementia in Latin America: Epidemiological Evidence and Implications for Public Policy.

Front. Aging Neurosci. 9:221. doi: 10.3389/fnagi.2017.00221

\section{Dementia in Latin America: Epidemiological Evidence and Implications for Public Policy}

\author{
Nilton Custodio ${ }^{1 *}$, Ana Wheelock ${ }^{2,3}$, Daniela Thumala ${ }^{2,4}$ and Andrea Slachevsky $2,5,6,7,8 *$ \\ ${ }^{1}$ Unidad de diagnóstico de deterioro cognitivo y prevención de demencia, Departamento de Neurología, Instituto Peruano de \\ Neurociencias, Lima, Peru, ${ }^{2}$ Gerosciences Center for Brain Health and Metabolism (GERO), Santiago, Chile, ${ }^{3}$ Department of \\ Surgery and Cancer, National Institute for Health Research Imperial Patient Safety Translational Research Centre, Imperial \\ College London, London, United Kingdom, ${ }^{4}$ Psychology Department, Faculty of Social Sciences, Universidad de Chile, \\ Santiago, Chile, ${ }^{5}$ Physiopathology Department, ICBM, and East Neuroscience Department, Faculty of Medicine, Universidad \\ de Chile, Santiago, Chile, ${ }^{6}$ Cognitive Neurology and Dementia Unit, Neurology Department, Hospital del Salvador, Santiago, \\ Chile, ${ }^{7}$ Center for Advanced Research in Education (CIAE), Universidad de Chile, Santiago, Chile, ${ }^{8}$ Servicio de Neurología, \\ Departamento de Medicina, Clínica Alemana-Universidad del Desarrollo, Santiago, Chile
}

Population aging is among the most important global transformations. Today, $12 \%$ of the world population is of age 60 and over and by the middle of this century this segment will represent $21.5 \%$. The increase in population of those aged 80 and over, also referred to as the "oldest old" or the "very elderly", will be even more pronounced, going from $1.7 \%$ of the population to $4.5 \%$ within the same period. Compared to European and North American countries, Latin America $(\llcorner A)$ is experiencing this unprecedented demographic change at a significantly faster rate. Due to demographic and health transitions, the number of people with dementia will rise from 7.8 million in 2013 to over 27 million by 2050. Nowadays, the global prevalence of dementia in LA has reached $7.1 \%$, with Alzheimer's Disease (AD) being the most frequent type. This level is similar to those found in developed countries; however, the dementia rate is twice as high as that of the 65-69 years age group in developed countries. In addition, the prevalence and incidence of dementia is higher among illiterate people. Mortality rates due to dementia have risen considerably. The burden and costs of the disease are high and must be covered by patients' families. The prevention of dementia and the development of longterm care policies and plans for people with dementia in LA, which take into account regional differences and similarities, should be urgent priorities.

Keywords: Latin America, dementia, epidemiology, public policy, Alzheimer, dementia plan, caregiver burden, cost of dementia

\section{INTRODUCTION}

Population aging is among the most important global transformations. Today, $12 \%$ of the world population is of age 60 and over and by the middle of this century this segment will represent $21.5 \%$. The increase in population of aged 80 and over, also referred as the "oldest old" or the "very elderly", will be even more pronounced, rising from $1.7 \%$ of the population to $4.5 \%$ within the same period (United Nations, 2015). Compared to European and North American countries, Latin America (LA) is experiencing this unprecedented demographic change at a significantly faster rate (Bongaarts, 2009). Due to demographic and health transitions, the number of people with dementia in LA will rise from 7.8 million in 2013 to over 27 million by 2050 (Bupa and Alzheimer's Disease International, 2013; Baez and Ibáñez, 2016). The aim of this review is to provide an overview of the epidemiological state of affairs and a critical appraisal of the 
public policies that are being designed/implemented vs. those that are needed to address the current dementia-related challenges.

\section{THE PREVALENCE OF DEMENTIA IN LATIN AMERICA}

As a result of the demographic transition in LA, the total number of individuals over 60 years of age will increase, reaching approximately 57 million by 2025 (CEPAL, 2014). On the other hand, low socioeconomic and educational levels in the region are additional elements that account for the major increase in the prevalence of dementia. For these reasons, dementias are beginning to be regarded as a public health priority. Systematic reviews of studies on the prevalence of dementia conducted in developed countries have revealed a slightly downward trend for the USA and Europe, but an upwards trend for Asia (Winblad et al., 2016), The analysis of eight population studies conducted in Brazil, Cuba, Chile, Peru and Venezuela showed that the global prevalence is 7.1\% (confidence interval, CI 95\%: 6.8-7.4; Nitrini et al., 2009). The studies reveal that the prevalence of dementia increases with age, doubling every 5 years from 65 years of age onwards. It rises from $2.40 \%$ (CI 95\%: $2.11-2.72$ ) in the 60-64 group to $33.07 \%$ (CI 95\%: 29.98-36.20) in the 90-94 group (Nitrini et al., 2009). However, there is a significant variation in the estimate of prevalence of dementia, ranging from $2 \%$ in a Brazilian study (Ramos-Cerqueira et al., 2005) to $13 \%$ in a Venezuelan study (Maestre et al., 2002). These studies suggest prevalence similar to the ones reported for developed regions, whose rates range from $4.2 \%$ in Canada to $14.5 \%$ in Spain (Winblad et al., 2016). We must stress the fact that at least three studies, those conducted in Catanduva-Sao Paulo (Herrera et al., 2002; Nitrini et al., 2004) and Lima (Custodio et al., 2008), used the same screening tests for diagnosing dementia, while Llibre's study in Cuba (Llibre et al., 1999) used a uniform structured interview (Table 1).

With respect to the types of dementia found in the Brazilian city of Catanduva, $25 \%$ of the participants were assessed in their urban homes at $\geq 65$ years of age. Specialists examined those with suspected dementia. A $7.1 \%$ rate of dementia was found, with $55.1 \%$ of Alzheimer's Disease (AD) cases (Herrera et al., 2002). A similar protocol was used in Lima with a sample of 1532 individuals. 105 cases of dementia were found, with $\mathrm{AD}$ being the most frequent diagnosis

TABLE 1 | Prevalence of dementia: community-based studies 1994-2000 (Lopes et al., 2007).

\begin{tabular}{lccc}
\hline Age & $\begin{array}{c}\text { Number of } \\
\text { studies }\end{array}$ & $\begin{array}{c}\text { Prevalence of dementia } \\
\mathbf{( \% )}\left(\mathbf{C l}^{* *} \mathbf{9 5} \%\right)\end{array}$ & $\begin{array}{c}\text { Average increase in } \\
\text { prevalence }\end{array}$ \\
\hline $65-69$ & 17 & $1.2(0.8-1.5)$ & - \\
$70-74$ & 19 & $3.7(2.6-4.7)$ & 3.0 \\
$75-79$ & 21 & $7.9(6.2-9.5)$ & 2.1 \\
$80-84$ & 20 & $16.4(13.8-18.9)$ & 2.0 \\
$85-89$ & 16 & $24.6(20.5-28.6)$ & 1.5 \\
$90-94$ & 6 & $39.9(34.4-45.3)$ & 1.6 \\
$>95$ & 6 & $54.8(45.6-63.9)$ & 1.3 \\
\hline
\end{tabular}

${ }^{* *} \mathrm{Cl}$, confidence interval.
(56.2\%). This prevalence increased with age and was mostly observed in female participants (Custodio et al., 2008). AD is the most frequent cause of dementia in LA, representing $56.3 \%$ of cases, followed by $\mathrm{AD}$ with cerebrovascular disease (CVD), which reaches $15.5 \%$, and vascular dementia (VD), which accounts for $8.7 \%$. These results are consistent with those reported in previous research (Herrera et al., 2002; Nitrini et al., 2004; Ramos-Cerqueira et al., 2005). However, the fact that magnetic resonance imaging was not used may have distorted the true proportion of individuals with AD+CVD and VD (Grinberg et al., 2007; França-Resende et al., 2016).

Few studies conducted in our region have focused on other degenerative causes of dementia, such as frontotemporal dementia (FTD). Community-based studies conducted in LA with individuals aged $\geq 55$ years have found that the prevalence of FTD ranges from 12 to 18 cases per 1000 people, and that it is higher among Brazilians (2.6\%-2.8\%; Herrera et al., 2002; Lopes, 2006) than among Peruvians (1.90\%; Custodio et al., 2008) and Venezuelans (1.53\%; Maestre et al., 2002; Table 2). The values reported are intermediate with respect to global studies (Custodio et al., 2013). In general, the exact prevalence of FTD is unknown. The prevalence estimated in studies with outpatients and in European memory centers ranges from $0.002 \%$ to $0.031 \%$; from $0.078 \%$ to $1.56 \%$, and from $0.054 \%$ to $0.135 \%$ between 45 years and 64 years, 65 years and 74 years, and at $\geq 75$ years respectively (Rosso et al., 2003; Gilberti et al., 2012). However, recent community-based studies suggest that FTD may be more common than previously estimated (Bernardi et al., 2012). Borroni's (Borroni et al., 2010) in Brescia, Italy, reported a higher prevalence than the literature, reaching 17.6 cases per 100,000 people. This study encourages us to pay attention to FTD in people over 75 years old, in whom the prevalence reached $54 / 100,000$ inhabitants. The research examined suggests that the prevalence of FTD in LA may be lower than that reported for developed countries.

\section{THE INCIDENCE OF DEMENTIA IN LA}

In the study conducted in Catanduva, Sao Paulo (Nitrini et al., 2004), 1119 individuals aged $\geq 65$ years were reassessed on average 3.25 years after their first assessment, a process that revealed 50 cases of dementia (28 AD cases). The incidence rate of dementia was 13.8 per 1000 people/year for individuals $\geq 65$ years, while that of $\mathrm{AD}$ was 7.7. This is comparable to the levels reported by researchers working in Europe, North America and Asia (Satizabal et al., 2016). The incidence rate of dementia doubled every 5 years; however, it was found to be lower in the last 5-year period studied (Table 3). This may be due to the number of individuals in the age group over 90 years $(n=16)$, where only two new cases of dementia were found. This phenomenon has also been observed in other studies (Satizabal et al., 2016). In contrast with prior research, the study conducted in Catanduva (Nitrini et al., 2004) did not demonstrate any significant differences linked to gender; however, female participants displayed a high incidence of dementia, especially $\mathrm{AD}$, in very elderly groups (over 85 years of age). The incidence 
TABLE 2 | Prevalence of frontotemporal dementia in four studies conducted in Latin America (LA; adapted from Custodio et al., 2013).

\begin{tabular}{|c|c|c|c|c|c|c|c|}
\hline \multirow[t]{2}{*}{ Country } & \multirow[t]{2}{*}{ Location } & \multirow[t]{2}{*}{ Age group } & \multicolumn{3}{|c|}{ Prevalence } & \multicolumn{2}{|c|}{$\begin{array}{l}\text { Causes of } \\
\text { dementia }\end{array}$} \\
\hline & & & $\begin{array}{l}\text { Global dementia } \\
\qquad\left(95 \% \mathrm{Cl}^{\mathrm{a}}\right)\end{array}$ & FTD $^{b}$ & DUE $^{c}$ & $\begin{array}{l}\text { FTD } \\
(\%)\end{array}$ & $\begin{array}{l}\text { DUE } \\
(\%)\end{array}$ \\
\hline \multirow[t]{3}{*}{ Brazil (Herrera et al., 2002; Nitrini et al., 2004) } & Catanduva, Sao Paulo & $\geq 65$ & $7.1 \%(6.0-8.5)$ & $0.18 \%$ & $0.90 \%$ & 2.60 & 12.70 \\
\hline & Ribeirao Preto, Sao Paulo & $\geq 60$ & $6.0 \%(4.6-7.3)$ & $0.7 \%$ & $0.43 \%$ & 2.80 & 7.20 \\
\hline & & $\geq 65$ & $7.2 \%(5.7-8.6)$ & - & - & - & - \\
\hline \multirow[t]{2}{*}{ Venezuela (Maestre et al., 2002) } & Santa Lucia, Maracaibo & $\geq 55$ & $8.04 \%(7.01-9.19)$ & $0.12 \%$ & $0.45 \%$ & 1.53 & 5.61 \\
\hline & & $\geq 65$ & $13.27 \%^{\dagger}$ & - & - & - & - \\
\hline Peru (Custodio et al., 2008) & Cercado de Lima, Lima & $\geq 65$ & $6.85 \%(5.53-8.08)^{\ddagger}$ & $0.13 \%$ & $0.87 \%$ & 1.90 & 12.70 \\
\hline
\end{tabular}

${ }^{a} \mathrm{Cl}$, confidence interval; ${ }^{b} \mathrm{FTD}$, fronto-temporal dementia; ${ }^{c}$ DUE, dementia of unknow etiology; ${ }^{\dagger}$ data calculated by author; ${ }^{\ddagger}$ confidence interval data provided by author. Only raw, non-adjusted data are presented.

of dementia was higher in males than in females in the group $\leq 85$ years, although this difference was not statistically significant. The study carried out by the 10/66 Dementia Research Group with individuals $\geq 60$ years old living in urban areas of Cuba, the Dominican Republic and Venezuela and in urban and rural areas of Peru, Mexico and China (Prince et al., 2013) reported a higher incidence rate of dementia in women than in men and revealed that it increased exponentially with age. After standardizing the EURODEM incident cohort for age (analysis of four prospective studies conducted in Denmark, France, Netherlands and United Kingdom), the incidence rate of dementia according to $10 / 66$ criteria ranged from 20 to 30 per 1000 people/year, which is slightly higher than the 18.4 per 1000 people/year calculated according to the DSM-III-R criteria reported by the EURODEM. On the other hand, the incidence rates of dementia according to 10/66 criteria were approximately 1.5-2.5 times higher than those obtained with the DSM-IV dementia criteria.

\section{RISK FACTORS ASSOCIATED WITH DEMENTIA}

\section{The Influence of Age and Gender on the Prevalence of Dementia in LA}

According to studies conducted in LA, the prevalence of dementia increases with age: from $2.40 \%$ (95\% CI: $2.11-2.72$ ) in the 65-69 group to $20.20 \%$ (95\% CI: 18.62-21.78) in the 85-89 group and $33.07 \%$ (95\% CI: 29.98-36.20) among participants aged 90-94 years (Nitrini et al., 2004). These

TABLE 3 | Rate of incidence of dementia by age group and sex per 1000 inhabitants/year (adapted from Nitrini et al., 2004).

\begin{tabular}{|c|c|c|c|c|}
\hline Age & $N$ & $\begin{array}{c}\text { Women } \\
\text { (Cl** 95\%) }\end{array}$ & $\begin{array}{c}\text { Men } \\
\text { (CI 95\%) }\end{array}$ & $\begin{array}{c}\text { Total } \\
\text { (Cl 95\%) }\end{array}$ \\
\hline $65-69$ & 2 & $2.4(0.52-0.725)$ & $3.9(0.845-11.60)$ & $3.0(0.4-10.7)$ \\
\hline $70-74$ & 9 & $4.0(1.74-7.77)$ & $9.3(5.72-15.05)$ & $6.4(3.0-12.1)$ \\
\hline $75-79$ & 14 & 13.7 (9.36-23.87) & $20.5(14.04-32.92)$ & $16.4(9.1-27.1)$ \\
\hline 80-84 & 10 & 19.2 (3.87-32.05) & $35.8(21.12-58.66)$ & $25.0(12.2-44.4)$ \\
\hline 85-89 & 13 & 68.4 (5.13-98.60) & $24.3(11.64-45.83)$ & $48.2(26.5-77.8)$ \\
\hline$\geq 90^{* * *}$ & 2 & $44.0(9.46-113.46)$ & $34.2(7.38-91.74)$ & $38.5(4.8-118.0)$ \\
\hline
\end{tabular}

${ }^{* *} \mathrm{Cl}$, confidence interval, ${ }^{* * *}$ Only one patient (97) was over 94 years old. results confirm that the prevalence rates of dementia increase exponentially with age (Prince et al., 2016; Winblad et al., 2016).

In terms of gender, studies conducted in LA show higher rates for both men and women in the 65-69 years group, and for women in the 70-74 years group, compared with the results reported by European studies (Lobo et al., 2000; Nitrini et al., 2004; Winblad et al., 2016; Table 4). The studies carried out in LA reported slightly higher rates for female participants in all age groups (Nitrini et al., 2004). Similar rates were reported in studies conducted in Europe (Lobo et al., 2000; Winblad et al., 2016), LA, India and China (Prince et al., 2013). It is interesting to note that in LA, the prevalence in the 65-69 group is higher than in developed countries (Table 4). A number of reasons may be contributing to the greater prevalence observed in relatively young individuals in developing countries, especially their limited access to primary care and their low educational level. The lack of primary health care can predispose these individuals to suffering from dementia caused by controllable or curable diseases, such as hypertension or syphilis. Low educational levels have been consistently linked to high dementia rates; in this regard, it can be argued that low educational levels are linked to early manifestations of cognitive decline, whereas individuals with higher educational levels tend to have a cognitive reserve that delays the emergence of clinical signs of dementia (Fratiglioni and Wang, 2007; Manly et al., 2007).

\section{The Influence of Education on Dementia}

An inverse relationship has been demonstrated to exist between educational level and dementia. The prevalence of dementia in Lima reached $3.7 \%$ in individuals with more than 8 years of education, but it was much higher (15.2\%) in illiterate participants (Custodio et al., 2008). Through a univariate analysis, the study conducted in Catanduva also revealed a greater incidence of dementia among illiterate participants; however, a multivariate analysis showed that the relationship was more significant when controlling for age and female sex (Nitrini et al., 2004). In Chile, two studies reported higher prevalence of cognitive impairment and dementia in rural contexts and in people with low educational levels: cognitive impairment was 5.6 times higher among adults with low educational levels $(17.2 \%)$ compared to those with high educational levels 
TABLE 4 | Comparison of dementia prevalence associated with gender considering data provided by seven LA studies and European studies (adapted from Nitrini et al., 2009).

\begin{tabular}{|c|c|c|c|c|c|c|c|c|}
\hline \multirow[b]{3}{*}{ Age } & \multicolumn{5}{|c|}{ Latin American studies } & & \multicolumn{2}{|c|}{ European studies } \\
\hline & \multicolumn{3}{|c|}{ Women } & \multicolumn{3}{|c|}{ Men } & \multirow{2}{*}{$\begin{array}{c}\text { Women } \\
\begin{array}{c}\text { Mean } \\
(\%)\end{array}\end{array}$} & \multirow{2}{*}{$\begin{array}{c}\text { Men } \\
\begin{array}{c}\text { Mean } \\
(\%)\end{array}\end{array}$} \\
\hline & $\begin{array}{c}\text { Dementia } \\
\mathbf{N}\end{array}$ & $\begin{array}{c}\text { Participants } \\
N\end{array}$ & $\begin{array}{l}\text { Mean (\%) } \\
\left(95 \% \mathrm{Cl}^{* *}\right)\end{array}$ & $\begin{array}{c}\text { Dementia } \\
\mathbf{N}\end{array}$ & $\begin{array}{c}\text { Participants } \\
\text { N }\end{array}$ & $\begin{array}{c}\text { Mean (\%) } \\
(95 \% \mathrm{Cl})\end{array}$ & & \\
\hline $65-69$ & 149 & 5620 & $\begin{array}{c}2.65 \\
(2.25-3.10)\end{array}$ & 79 & 3479 & $\begin{array}{c}2.27 \\
(1.80-2.81)\end{array}$ & 1.0 & 1.6 \\
\hline $70-74$ & 196 & 4781 & $\begin{array}{c}4.10 \\
(3.55-4.69)\end{array}$ & 65 & 2317 & $\begin{array}{c}2.81 \\
(2.17-3.57)\end{array}$ & 3.1 & 2.9 \\
\hline $75-79$ & 293 & 3802 & $\begin{array}{c}7.71 \\
(6.89-8.59)\end{array}$ & 112 & 1888 & $\begin{array}{c}5.93 \\
(4.90-7.09)\end{array}$ & 6.0 & 5.6 \\
\hline $80-84^{*}$ & 291 & 2326 & $\begin{array}{c}12.51 \\
(11.17-13.94)\end{array}$ & 162 & 1489 & $\begin{array}{c}10.88 \\
(9.34-2.55)\end{array}$ & 12.6 & 11.0 \\
\hline 85-89 & 281 & 1244 & $\begin{array}{c}22.59 \\
(20.30-24.97)\end{array}$ & 182 & 960 & $\begin{array}{c}18.96 \\
(16.49-21.55)\end{array}$ & 20.2 & 12.8 \\
\hline $90+$ & 189 & 500 & $\begin{array}{c}37.80 \\
(33.56-42.28)\end{array}$ & 105 & 390 & $\begin{array}{c}26.92 \\
(22.54-31.67)\end{array}$ & 30.8 & 22.1 \\
\hline
\end{tabular}

${ }^{* *} \mathrm{Cl}$, confidence interval.

(3\%; González et al., 2009; ENS, 2010; Fuentes and Albala, 2014).

The systematic review published by Sharp and Gatz (2011), which involved 71 studies conducted in the last 25 years, suggests that the education-dementia link may be more complex. This may be due to the fact that differences in terms of the methodologies and samples used make it difficult to compare studies; however, the analysis of the educational factor could have a differential impact in different cultures and cohorts. The mechanisms that have been advanced to explain the education-dementia link include cerebral reserve and cognitive reserve (Stern, 2009), which appear to be robust. Likewise, there is consensus among researchers that education is a protective factor against dementia (CaamañoIsorna et al., 2006; Baumgart et al., 2015). Within the context of the cognitive reserve hypothesis, if two individuals with the same brain volume suffer from dementia, the one with the largest cognitive reserve is believed to be better equipped to tolerate the cerebral pathological burden for longer, thus delaying the first clinical manifestations of the disease (Qiu et al., 2001). In addition, the survival rates of patients with dementia and high education levels are low compared with those of patients with low education levels (Qiu et al., 2001). Stern's theoretical explanation (Stern, 2012) is that, when individuals with high cognitive reserves reach the point where cognitive function is affected, they have a cerebral pathological burden nearing their total capacity, and at that point clinical manifestations are florid and evolve quickly, which resembles rapidly progressive dementia. On the other hand, it is interesting to trace the influence of non-modifiable risk factors such as allele $\varepsilon 4$ of apolipoprotein E (APOE) and its effect considering education level. In this regard, there are no doubts of the role of APOE $\varepsilon 4$ as a risk factor for $\mathrm{AD}$; however, education may be relevant for balancing the effect of APOE $\varepsilon$ on the clinical manifestations of dementia. Only a few studies have been conducted on the latter issue. An analysis of the data yielded by three studies conducted in Northern Europe (Sweden and Finland) with 3436 participants over 65 years old suggests that genetic factors (APOE \&4) and environmental factors (education) may act independently as risk factors for dementia; in addition, they may interact: high education levels could balance the negative effects of APOE $\varepsilon 4$ on the occurrence of dementia (Wang et al., 2012). There is no information about the influence of education and Apo-E on AD.

\section{DEMENTIA-RELATED MORTALITY}

People living with dementia have a risk of death 2-4 times higher than that of similarly aged people without dementia (Ientile et al., 2013). In middle-income countries, the mortality risk is 1.56-5.69 times higher than in individuals without dementia (Nitrini et al., 2005). Survival after a dementia diagnosis ranges from 3 years to 12 years, depending on diagnostic criteria, age, severity at the time of diagnosis, and place of diagnosis (Brodaty et al., 2012; Kua et al., 2014). Fitzpatrick et al. (2005) reported an average survival rate of 7.1 years (95\% CI: $6.7-7.5$ years) for $\mathrm{AD}$ and 3.9 years (3.5-4.2 years) for VD. Helzner et al. (2008), using a multi-ethnic cohort of 323 individuals in the USA, described that $\mathrm{AD}$ reduced life expectancy by 3 years in subjects diagnosed between 70 years and 75 years of age, and by 1-2 years when diagnosis was made at a later age. In advanced dementia cases, average survival reached 1.3 years, with a mortality rate of $25 \%$ at 6 months. Similarly, Mitchell et al. (2009), with a cohort of 323 nursing home patients with advanced dementia, report an average survival time of 1 year and 3 months and a mortality risk of $24.7 \%$ at 6 months. At 18 months of evolution, more than $54.8 \%$ of patients had died. Severe dementia often causes complications such as immobility, swallowing disorders and malnutrition, thus increasing the risk of developing intercurrent diseases that may cause death. It has been reported that in the last 3 months of survival, $37.3 \%$ of patients suffered from pneumonia, $32.2 \%$ had a fever, and 90.4\% displayed swallowing disorders. Pneumonia has been identified as the complication most frequently leading to death 
(Mitchell et al., 2009; for a review, see Slachevsky et al., 2016).

A more than threefold increase in dementia-related mortality was observed between 1990 and 2010; thus, the number of deaths went up from 141,200 (CI 95\% 110,800-208,500) to 485,700 (CI $95 \% 307,800-590,500)$, which represents a $244 \%$ increase. The age-adjusted mortality rate rose from 3.6 (CI 95\% 2.8-5.4) to 7.1 (CI 95\% 4.5-8.6) per 100,000 inhabitants, which constitutes a $95.4 \%$ increase. Globally, $\mathrm{AD}$ and other dementias are the 50th cause of death (Prince et al., 2016). In the Andean part of LA, they are the 68th cause and the 53th in South America, with major intra-regional disparities (Lozano et al., 2012; Prince et al., 2016). In Chile, in 2012, with 3852 deaths $(3.89 \%$ of the total number of deaths), dementias constituted the sixth specific cause of death (Lozano et al., 2012). A global study on disease burden conducted in 2010 showed that the number of deaths attributed to dementias rose by $526 \%$, which means that they are the cause of death with the largest increase in percentage (Lozano et al., 2012). In Chile, regional variability has been reported with respect to dementia-related mortality. Two regions display higher rates: the Metropolitan Region, in the center of the country, and Antofagasta, in the north (Russ et al., 2016). It has been suggested that this difference may be due to the high urbanization rates of these regions and/or to pollution (Russ et al., 2016). Nevertheless, dementiarelated mortality data should be interpreted with caution. This is because many people living with dementia are not formally diagnosed (Lang et al., 2017) and few physicians have received dementia training, thus they may underreport dementia as a cause of death (O'Neill et al., 2013; Olavarría et al., 2016; Russ et al., 2016). Since a formal diagnosis is required for it to be recorded on a death certificate, it is possible that dementia underdiagnosis is affecting the accuracy of data on dementia-related mortality (Russ et al., 2016).

\section{THE IMPACT OF DEMENTIAS}

\section{Disease Burden}

The DALY (disability-adjusted life years) index is used to measure and compare disease burdens in the population. It represents the sum of the years lost due to premature death and the years lost as a result of disability (Alzheimer's Association, 2014). The World Health Organization has estimated that dementias contribute with $11.2 \%$ of the years of life with disability in people over 60 years old, which is higher than the time added by, cardiovascular diseases and cancer (Ballard et al., 2011). A global study of disease burden conducted in 2010 showed that the DALYs due to AD and other dementias rose from 5,695,000 (4,516,000-6,982,000) in 1990 to $11,349,000$ $(9,147,000-1,3741,000)$ in 2010 , representing a $99.3 \%$ increase. The DALYs per 100,000 people increased from 107 (85-132) in 1990 to $165(133-199)$ in 2010, representing a $53.3 \%$ increase. Globally, dementias are the 49th disease in terms of DALYs. In Central America, they occupy the 50th spot, the 62nd in Andean LA and the 26th in South America (Murray et al., 2012). In Chile, they are the fastest-growing diseases in terms of DALY causation: 200\% between 1990 and 2010 (Murray et al., 2012). Likewise, dementias are the fastestgrowing diseases in terms of premature death causes, rising from the 49th place in 1990 to the 17th in 2010 (Lozano et al., 2012).

\section{Burden of Caring}

A high proportion of people with dementia need care ranging from the provision of instrumental daily living activities to full personal care and round-the-clock supervision (Sorensen et al., 2006). Therefore, dementia affects not only the patient, but also the person who supports them, which effectively doubles the number of people concerned (Ferrario et al., 2003; Georges et al., 2008). Caregivers are either formal, i.e., people who are paid to care for a patient with dementia, such as healthcare professionals, or informal, i.e., individuals who provide care and/or support to a family member, friend or neighbor who is chronically ill, frail, or who has a physical or mental disability (Slachevsky et al., 2013). In Latin American societies, patients with dementia are mainly cared for by families, and to a lesser extent by public institutions. That is, care and attention are provided by people who are physically and emotionally close to them and who have the largest responsibility in the ill person's care, despite having no prior training and receiving no payment. Several studies have examined informal caregivers, two of which included samples with more than 200 subjects. In Chile, the CUIDEME study involved 292 family caregivers who lived mainly in Santiago, the capital city. There were more female $(80 \%)$ than male caregivers. Most of them were daughters and spouses of the patients. Severe burden was reported in $63 \%$ of the caregivers, and $47 \%$ exhibited psychiatric morbidity. Burden was associated with caregiver psychiatric distress, family dysfunction, severity of neuropsychiatric symptoms, and functional disability, but neither the patient's age, gender, nor socioeconomic status (SES) impacted burden (Slachevsky et al., 2013). In Cuba, in a descriptive study with 237 caregivers, a survey was administered to informal caregivers of elderly people with ictus and dementia, who resided in the Abel Santamaría neighborhood of Santiago de Cuba. The analysis demonstrated that $71.7 \%$ of caregivers were female and $28.3 \%$ male. Their average age was 49.83 years, and the average time devoted to the task was 42.86 months. $49.4 \%$ of the caregivers were children or partners of the people with dementia studied. $53.2 \%$ were full-time caregivers, while $46.7 \%$ worked part-time (Turtós Carbonell et al., 2016). In Bogotá, Colombia, in a descriptive study conducted with 52 informal caregivers of patients with Alzheimer's, $82.7 \%$ of whom were female, $57.7 \%$ of the population was not aware of any support networks. $36.5 \%$ of the caregivers were $51-60$ years old and $25.0 \%$ were between 41 years and 50 years old. $23.1 \%$ were under 40 years old, $9.6 \%$ were $61-70$ years old, and only $5.8 \%$ were over 70. $55.8 \%$ of the caregivers were children of the patients and $30.8 \%$ were their spouses. $55.8 \%$ of the caregivers reported caring for a person with $\mathrm{AD}$ for 36 months and $34.6 \%$ did so between 13 months and 36 months. $36.5 \%$ of the caregivers were housewives, $26.9 \%$ were pensioners, $25 \%$ were in work, and $5.8 \%$ were unemployed. Caregiver depression, assessed with 
the State-Trait Depression Inventory, occurs due to taking care of a person who is ill (Cerquera Córdova et al., 2012). In Peru, in three research centers located in Lima, 92 informal caregivers were interviewed to analyze their caregiver burden with the Zarit Burden Interview (ZBI) and the Beck Depression Inventory (BDI-II). In this sample, $75 \%$ of the participants were over 55.5 years old. Most were female (81.5\%) and spouses of the patient $(60.87 \%)$. In addition, over $75 \%$ of them had been a caregiver for at least 1 year, $90.2 \%$ considered that their leisure time had been reduced, and $83.7 \%$ felt that their health had deteriorated. This study demonstrated that caregivers display high burden levels. Also, a multivariate analysis revealed that only the BDI-II was a solid predictor of ZBI (Custodio et al., 2014). In Brazil, at the Center for $\mathrm{AD}$ of the Federal University of Rio de Janeiro, 145 caregivers were interviewed to analyze three dimensions of caregiver burden: emotional exhaustion (EE), depersonalization (DP) and reduced personal accomplishment (RPA). In addition, the researchers studied the demographic characteristics of the patients' caregivers and clinics. High levels of EE were present in $42.1 \%$ of the sample, while DP was found in $22.8 \%$. RPA was present in $38.6 \%$ of the participating caregivers. Caregiver depression and patient delusions were the most significant predictors of EE (Truzzi et al., 2012). Similarly, in a sample of people living in Sao Paulo, 165 caregivers of patients with dementia (61 with $\mathrm{AD}, 25$ with some cognitive impairment but not dementia, and 79 healthy controls) were interviewed to assess caregiver burden according to the ZBI and establish correlations with the results of the patients' Neuropsychiatric Inventory (NPI). This study demonstrated that neuropsychiatric symptoms are significantly associated with caregiver stress (Cunha Folquitto et al., 2013).

\section{Economic Cost of Dementia}

In 2010, the total estimated worldwide cost of dementia was US\$ 817.9 billion, roughly one percent of the global gross domestic product (GDP). This cost has three components: (i) direct costs that include medical expenses (visits, tests, medication); (ii) social costs associated with paid formal caregiving by health professionals or institutionalization; and (iii) indirect costs associated with informal caregivers-family members, friends, or neighbors-who are unpaid but forgo paid jobs and thereby suffer a productivity loss. The level and composition of the cost of dementia varies widely across countries. In high-income countries, the cost is 1.2 percent of GDP and is mostly formal. In contrast, in low-income countries it is just 0.24 percent of GDP and most costs are informal (World Health Organization and Alzheimer's Disease International, 2012; WHO, 2015). In contrast with high-income countries, informal care costs predominate in low and mid-low income countries. The costs of community care by paid social caregivers and home caregivers are practically nonexistent (Wimo et al., 2017). Only a handful of studies have focused on the cost and heterogeneity of the instruments used to assess the costs involved. Allegri et al. (2007), using a sample of 80 communitydwelling patients with dementia and 25 institutionalized patients, reported that direct costs increased according to the degree of cognitive deterioration (US\$ 3420.40 in mild cases and US\$ 9657.60 in severe cases) and institutionalization (US\$ 3189.20 for outpatients vs. US\$ $14,447.68$ for institutionalized patients). Costs also differ depending on the type of dementia (US\$ 5112 for VD, US\$ 4625 for AD and US\$ 4,924 for FTD). In Peru, Custodio et al. (2015), using a sample of 136 outpatients receiving care at a private clinic, reported an average cost of US\$ 1500 per trimester for AD, US\$ 1860 for FTD and US\$ 1291 for VD. These costs are significantly greater than those of patients without dementia (US\$ 230). Families are reported to spend a large part of their income on the care of people with dementia. In Brazil, Veras et al. (2008) reported that direct costs represent approximately $66 \%$ of family income, ranging from $75 \%$ in mild stages to $62 \%$ in severe stages, a figure that reaches $81 \%$ in the case of comorbidities such as high blood pressure and diabetes. Liu (2013) (unpublished data cited in Prince et al., 2015) reported a higher cost of public care (US\$ 6750) compared to private care (US\$ 1887), with both values being calculated using international dollars. In Chile, Hojman et al. (2017), using a sample of 330 informal primary caregivers, reported an average monthly cost per patient of US\$ 943. Direct medical costs account for $21 \%$, direct social costs represent $5 \%$, and indirect costs constitute $74 \%$ of the total figure. The mean monthly cost is inversely related to SES. The monthly cost for high SES is US\$ 690 and US\$ 1023 for low SES. In this study, between one third and one half of the variation explained by SES is not due to the severity gradient, suggesting that SES is a key determinant in the cost of dementia, regardless of severity.

In contrast with high income countries, LA is characterized by the predominance of informal care costs (Wimo et al., 2010). Medical costs represent a relatively small percentage of the total costs of dementias. Costs associated with community care provided by paid social caregivers and home caregivers are practically nonexistent, which may be due to the lack of developed health services that can meet the needs of patients with chronic, non-transmissible diseases such as dementia (Hojman et al., 2017).

It is important to stress that the studies mentioned above have major limitations, including the fact that they employed convenience sampling and only enrolled patients diagnosed with dementias and who were being medically monitored. For this reason, these results must be extrapolated cautiously, considering that most people with dementias do not receive medical care.

\section{NATIONAL DEMENTIA POLICIES}

In LA, outdated health systems have failed to provide the complex and multidisciplinary actions required by people with chronic diseases such as dementia (Bossert and Leisewitz, 2016). Following recommendations by the WHO, the Pan American Health Organization and NGOs such as AD International (World Health Organization and Alzheimer's Disease International, 2012), several LA countries have started to develop national strategies to address the dementia crisis. Yet, much work remains to be done.

One of the countries spearheading these efforts in the region is Costa Rica, who launched in 2014 a National Plan for AD and 
ACTIONS FOR DEMENTIA IN THE HEALTH SECTOR

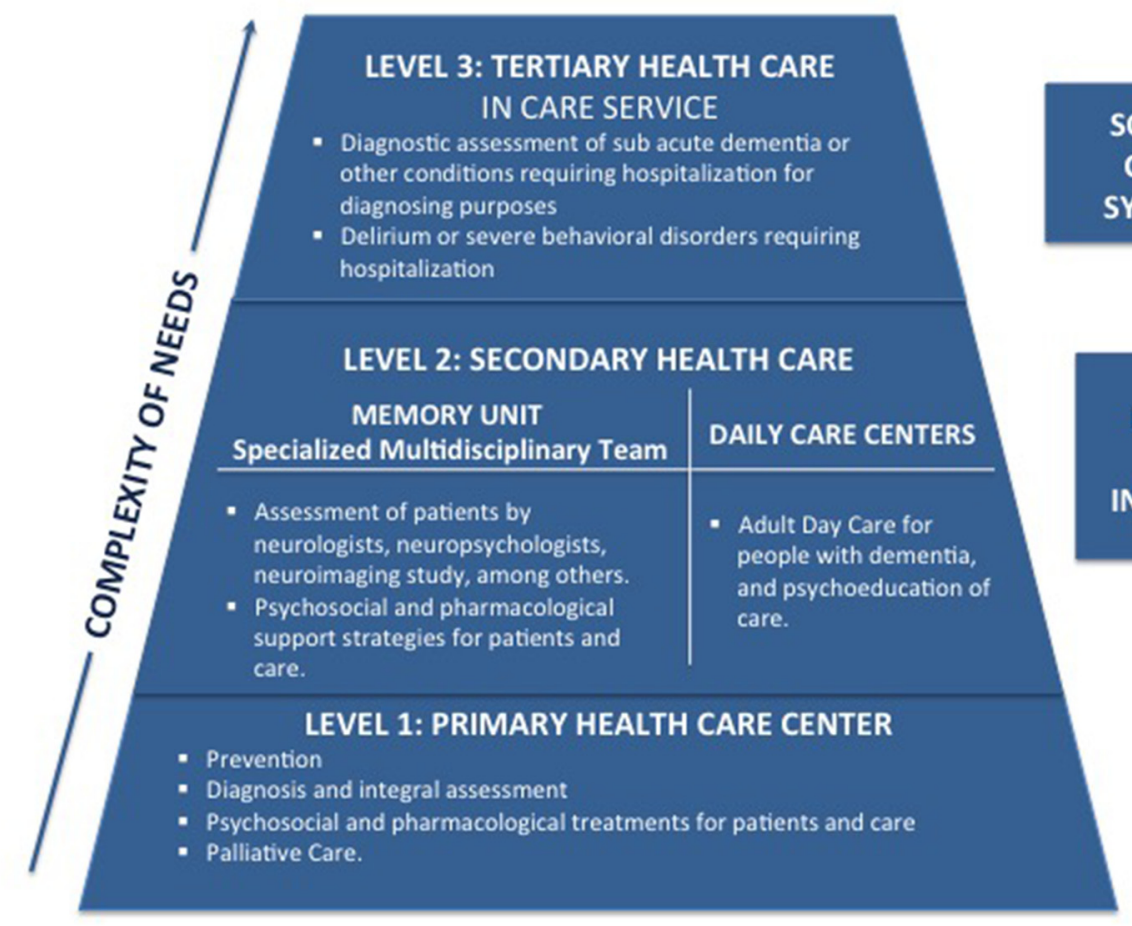

ACTIONS FOR DEMENTIA IN OTHER AREAS

\section{SOCIAL \\ CARE \\ SYSTEM}

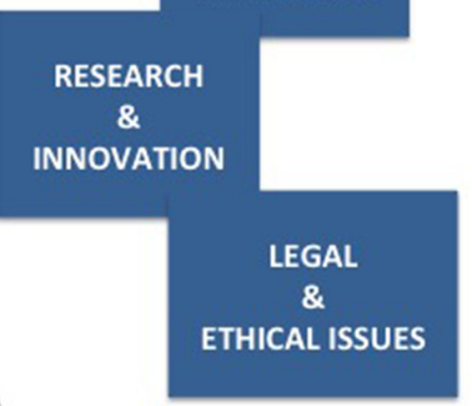

FIGURE 1 | Biopsychosocial model of dementia care in the Chilean's National Dementia Plan (adapted from Ministerio de Salud, 2015) (prepared by AS).

Related Diseases (Conapam, 2014). The plan's original objectives were transformed into seven cross-cutting principles which are guiding its implementation: (1) human rights of people with dementia; (2) empowerment and participation of people with dementia and their caregivers; (3) evidence-based practices for risk reduction and dementia care combined with research in the public and private sectors; (4) multisectoral collaboration on the response of public health to dementia; (5) health, social and community coverage for dementia; (6) equality in the response of public health in relation to dementia; and (7) care, prevention, promotion and rehabilitation treatment and development of dementia care. In 3 years, Costa Rica has implemented a number of initiatives, including community and clinical memory centers, programs, facilities and training for caregivers, acquisition of neuroimaging equipment, access to medication approved for Alzheimer's through the social security system, among others.

In 2016, Argentina launched the National Strategic Plan for a Healthy Brain, AD and other Dementias (PAMI, 2016). The plan encompasses five key areas: improving awareness, training professionals, caregivers and family members, improving access to diagnosis and treatment, reducing risk and encouraging research. Its implementation is underway.

In 2015, the Chilean government implemented an intersectoral work group-comprised of experts in neurology, geriatrics, mental health, public policy and the civil society-to propose a National Plan for Dementia (Ministerio de Salud, 2015). The plan was submitted to public consultation and has yet to be officially launched (Gajardo and Abuseleme, 2016). Nevertheless, the plan is currently being implemented and funding has been granted for Memory Clinics in secondary health care facilities, for a pilot program for dementia in primary care facilities and for dementia care training for health professionals (Figure 1).

In addition, since 2013, the government of Chile has funded daily care facilities for dementia patients, which are an important component of the dementia plan.

Other countries, however, are lagging behind. Bolivia, for example, has approved specific laws for people with dementia, but no financial commitments have been made. In 2013, Mexico's National Institutes of Geriatrics, Neurology and Psychiatry developed a proposal for a National Dementia Plan. Its primary aim was to promote the well-being of people affected by $\mathrm{AD}$ and theirs caregivers and families through the strengthening of the Mexican healthcare system and the support of other responsible institutions (Gutiérrez-Robledo and Arrieta-Cruz, 2015). However, this plan has yet to be approved by the government.

Given the challenges posed by the increasing number of people living with dementia, LA countries' current efforts to 
tackle the looming dementia crisis are simply insufficient. Governments must urgently work toward closing the gap between the need for prevention, treatment and care of dementia and the actual provision of these services (World Health Organization and Alzheimer's Disease International, 2012). National dementia policies also need to consider how key contextual factors such as poverty, inequality and limited resources, impact the health of the population and access to health services (Marmot, 2005; Baez and Ibáñez, 2016; Bossert and Leisewitz, 2016; Hojman et al., 2017).

With regard to prevention, policies must address the challenges posed by a higher prevalence of dementia in groups with less education, by the increased incidence of cardiovascular diseases, which in turn, are associated with a higher risk of dementia, and by economic and geographical barriers to access to health services (Glassman et al., 2010; Garcia-Subirats et al., 2014). Dementia prevention efforts should also be shared by other government departments. For instance, recent evidence suggests that improvement in living conditions and higher levels of formal education account for a reduced risk of dementia in later life (Wu et al., 2017). Thus, increasing access to formal education could contribute to reduce the prevalence of dementia in LA (Meng and D'arcy, 2012).

A key policy challenge is that access to appropriate support services for people with dementia is hindered by the low level of detection of dementia in LA (Lang et al., 2017). This is largely due to the social stigma associated with dementia and lack of dementia awareness both among the general public and healthcare professionals. Therefore, efforts should also focus on addressing these barriers (Romero and Ge, 2007; Maestre, 2012; Olavarría et al., 2016).

A related obstacle to dementia diagnosis is the lack of validated and standardized instruments to assess functionality and cognition in illiterate and low-educated populations and populations with diverse cultural background, such as indigenous population vs. city population (Maestre, 2012; Parra, 2014).

An important question is when in the course of the dementia syndrome it is advisable to make a diagnosis. There is currently an intense debate about the benefits and drawbacks of early diagnosis vs. timely diagnosis-the latter being defined as the access to accurate diagnosis at a time in the disease process when it can be of most benefit for the patient (Le Couteur et al., 2013). From a public health perspective, the available evidence suggests that there is no benefit in screening for cognitive impairment at the population level, and that both screening and early diagnosis could actually cause harm (Boustani et al., 2003; Le Couteur et al., 2013). In the absence of a cure for $\mathrm{AD}$ and other neurodegenerative dementias, timely diagnosis is, therefore, recommended (Brooker et al., 2014). Nevertheless, the concept of timely diagnosis is ill-defined in the field of dementia. For some scholars, it corresponds to a diagnosis in the presence of neuropathology, early cognitive changes and possible disability and subjective impairment, i.e., at a stage that overlaps with early diagnosis (Dubois et al., 2016). For others, timely diagnosis corresponds to either a diagnosis established at the onset of cognitive decline and disability, responding to patient and caregivers' concerns, or to a diagnosis established in the presence of significant evidence of cognitive decline and disability (Prince et al., 2011; Brooker et al., 2014). In LA, the benefits and disadvantages associated with the diagnosis of dementia at different stages should be evaluated and a clear definition of timely diagnosis within the LA context should be sought. We argue that given the high rate of undetected dementia, the prevailing misconceptions on aging, the low awareness of dementia in the general public and health professionals, inadequate training in dementia among health professionals, and little access to specialist service, the benefit of case detection for "at risk" groups needs to be discussed (Baez and Ibáñez, 2016; Manes, 2016; Lang et al., 2017).

Concerning treatment and care, most LA countries have outdated health systems which are not currently able to offer the resource-intensive and multidisciplinary programs that people with dementia and their caregivers require (Bossert and Leisewitz, 2016). The capacity to develop integrated health and social care services for patients with dementia continues to challenge both developed and developing economies and will certainly be paramount to the success of public policies attempting to address the rising tide of dementia. Meanwhile, raising public awareness about dementia and ensuring that those living with these illnesses are treated with respect and dignity should be a priority (Gajardo and Abuseleme, 2016; Slachevsky and Gajardo, in press).

\section{CONCLUSIONS}

The increase in the prevalence of dementia and the resulting economic and societal impact, are growing concerns in LA. Yet, only a handful of epidemiological studies examining the prevalence of risk and dementia types, and protective factors, have been conducted in the region. Moreover, there is scarce information regarding the socio-sanitary conditions of people with dementia, their environment and associated costs. Among other issues, there is no data evaluating the impact of diagnosis and access to socio-sanitary support services on the evolution of the disease. From a public health perspective, the vast and rapid increase in the number of people with dementia due to demographic and health changes, warrants the prioritization of both dementia prevention policies long-term strategies to provide care for people living with dementia (Sousa et al., 2010).

Finally, it should be noted that although LA can be considered as a whole, its levels of development are heterogeneous. Risk factors associated with dementia, as well as its social impact varies between countries and within each country. Therefore, research and public policies in this field require consideration of the similarities that characterize the LA region, as well as its differences and particularities.

\section{AUTHOR CONTRIBUTIONS}

All the authors developed the study concept, drafted the manuscript and approved its final version. 


\section{ACKNOWLEDGMENTS}

AS is supported by Comisión Nacional de Investigación Científica y Tecnológica (CONICYT)/FONDECYT/11404223, CONICYT/FONDAP/15150012 and Associative Research Program of CONICYT under Basal Funds Grant for Centers

\section{REFERENCES}

Allegri, R. F., Butman, J., Arizaga, R. L., Machnicki, G., Serrano, C., Taragano, F. E., et al. (2007). Economic impact of dementia in developing countries: an evaluation of costs of Alzheimer-type dementia in Argentina. Int. Psychogeriatr. 19, 705-718. doi: 10.1017/s1041610206003784

Alzheimer's Association. (2014). 2014 Alzheimer's disease facts and figures. Alzheimers Dement. 10, e47-e92. doi: 10.1016/j.jalz.2014.02.001

Baez, S., and Ibáñez, A. (2016). Dementia in Latin America: an emergent silent Tsunami. Front. Aging Neurosci. 8:253. doi: 10.3389/fnagi. 2016.00253

Ballard, C., Gauthier, S., Corbett, A., Brayne, C., Aarsland, D., and Jones, E. (2011). Alzheimer's disease. Lancet 377, 1019-1031. doi: 10.1016/S01406736(10)61349-9

Baumgart, M., Snyder, H. M., Carrillo, M. C., Fazio, S., Kim, H., and Johns, H. (2015). Summary of the evidence on modifiable risk factors for cognitive decline and dementia: a population-based perspective. Alzheimers Dement. 11, 718-726. doi: 10.1016/j.jalz.2015.05.016

Bernardi, L., Frangipane, F., Smirne, N., Colao, R., Puccio, G., Curcio, S. A., et al. (2012). Epidemiology and genetics of frontotemporal dementia: a door-to-door survey in southern Italy. Neurobiol. Aging 33, 2948.e1-2948.e10. doi: 10.1016/j. neurobiolaging.2012.06.017

Bongaarts, J. (2009). Human population growth and the demographic transition. Philos. Trans. R. Soc. Lond. B Biol. Sci. 364, 2985-2990. doi: 10.1098/rstb. 2009.0137

Borroni, B., Alberici, A., Grassi, M., Turla, M., Zanetti, O., Bianchetti, A., et al. (2010). Is frontotemporal lobar degeneration a rare disorder? Evidence from a preliminary study in Brescia county, Italy. J. Alzheimers Dis. 19, 111-116. doi: 10.3233/JAD-2010-1208

Bossert, T. J., and Leisewitz, T. (2016). Innovation and change in the Chilean health system. N. Engl. J. Med. 374, 1-5. doi: 10.1056/NEJmp1514202

Boustani, M., Peterson, B., Hanson, L., Harris, R., Lohr, K. N., and U.S. Preventive services task force (2003). Screening for dementia in primary care: a summary of the evidence for the U.S. Preventive Services Task Force. Ann. Intern. Med. 138, 927-937. doi: 10.7326/0003-4819-138-11-200306030-00015

Brodaty, H., Seeher, K., and Gibson, L. (2012). Dementia time to death: a systematic literature review on survival time and years of life lost in people with dementia. Int. Psychogeriatr. 24, 1034-1045. doi: 10.1017/s10416102110 02924

Brooker, D., La Fontaine, J., Evans, S., Bray, J., and Saad, K. (2014). Public health guidance to facilitate timely diagnosis of dementia: Alzheimer's cooperative valuation in europe recommendations. Int. J. Geriatr. Psychiatry 29, 682-693. doi: 10.1002/gps.4066

Bupa, and Alzheimer's Disease International. (2013). Dementia in the Americas: Current and Future Cost and Prevalence of Alzheimer's Disease and Other Dementias. London: Bupa \& Alzheimer's Disease International.

Caamaño-Isorna, F., Corral, M., Montes-Martínez, A., and Takkouche, B. (2006). Education and dementia: a meta-analytic study. Neuroepidemiology 26, 226-232. doi: 10.1159/000093378

CEPAL. (2014). La Nueva era Demográfica en América Latina y el Caribe. Primera reunión de la mesa directiva de la conferencia regional sobre población y desarrollo de América Latina y el Caribe. Santiago, Chile: Centro Latinoamericano y Caribeño de Población y Desarrollo (CELADE)-División de Población de la Comisión Económica para América Latina y el Caribe (CEPAL)

Cerquera Córdova, A. M., Pabón Poches, D. K., and Uribe Báez, D. M. (2012). Nivel de depresión experimentada por una muestra de cuidadores informales de pacientes con demencia de tipo Alzheimer. Psicol. Caribe 29, $360-384$. of Excellence FB 0003. AW and DT are supported by CONICYT/FONDAP/15150012. The authors would like to thank Asociación Costarricense de Alzheimer y otras Demencias Asociadas (ASCADA), for kindly providing up-to-date information about the progress of Costa Rica's National Plan for Alzheimer's Disease and Related Diseases.

Conapam. (2014). Plan Nacional para la Enfermedad de Alzheimer y Demencias Relacionadas 2014-2024 (National Plan for Alzheimer's Disease and Related Diseases 2014-2024). Costa RIca: Consejo Nacional de la persona adulta mayor (National Council of Older Persons).

Cunha Folquitto, J., Gomes Marques, R. C., Franciosi Tatsch, M., and Campos Bottino, C. M. (2013). Correlation between neuropsychiatric symptoms and caregiver burden in population-based sample from São Paulo, Brazil: a preliminary report. Dement. Neuropsychol. 7, 258-262. doi: 10.1590/s1980$57642013 \mathrm{dn} 70300005$

Custodio, N., García, A., Montesinos, R., Escobar, J., and Bendezú, L. (2008). Prevalencia de demencia en una población urbana de Lima-Perú: un estudio puerta a puerta. An. Fac. Med. 69, 233-238. doi: 10.15381/anales.v69i 4.1110

Custodio, N., Herrera-Perez, E., Lira, D., Montesinos, R., and Bendezú, L. (2013). Prevalence of frontotemporal dementia in community-based studies in Latin America: a systematic review. Dement. Neuropsychol. 7, 27-32. doi: 10.1590/s1980-57642013dn70100005

Custodio, N., Lira, D., Herrera-Perez, E., Nuñez Del Prado, L., Parodi, J. Guevara-Silva, E., et al. (2014). Informal caregiver burden in middle-income countries: results from Memory Centers in Lima-Peru. Dement. Neuropsychol. 8, 376-383. doi: 10.1590/s1980-57642014dn84000012

Custodio, N., Lira, D., Herrera-Perez, E., Nuñez Del Prado, L., Parodi, J., Guevara-Silva, E., et al. (2015). Cost-of-illness study in a retrospective cohort of patients with dementia in Lima, Peru. Dement. Neuropsychol. 9, 32-41. doi: 10.1590/s1980-57642015dn91000006

Dubois, B., Padovani, A., Scheltens, P., Rossi, A., and Dell'agnello, G. (2016). Timely diagnosis for Alzheimer's disease: a literature review on benefits and challenges. J. Alzheimers Dis. 49, 617-631. doi: 10.3233/JAD-150692

ENS. (2010). Encuesta Nacional de Salud 2009-2010. Santiago: Minsal.

Ferrario, S. R., Vitaliano, P., Zotti, A. M., Galante, E., and Fornara, R. (2003). Alzheimer's disease: usefulness of the family strain questionnaire and the screen for caregiver burden in the study of caregiving-related problems. Int. J. Geriatr. Psychiatry 18, 1110-1114. doi: 10.1002/gps.1021

Fitzpatrick, A. L., Kuller, L. H., Lopez, O. L., Kawas, C. H., and Jagust, W. (2005). Survival following dementia onset: Alzheimer's disease and vascular dementia J. Neurol. Sci. 229-230, 43-49. doi: 10.1016/j.jns.2004.11.022

França-Resende, E., Costa Silva, L., Carmona, K., Machado, T., Machado, J., Cerqueira GuimarãEs, H., et al. (2016). Ischemic cerebrovascular burden evaluated by magnetic resonance imaging in an elderly Brazilian community: the Pietà study. eNeurologicalSci 5, 30-34. doi: 10.1016/j.ensci. 2016.11.011

Fratiglioni, L., and Wang, H. X. (2007). Brain reserve hypothesis in dementia. J. Alzheimers Dis. 12, 11-22. doi: 10.3233/jad-2007-12103

Fuentes, P., and Albala, C. (2014). Aging and dementia in Chile. Dement. Neuropsychol. 8, 317-322. doi: 10.1590/s1980-57642014dn84000003

Gajardo, J., and Abuseleme, T. (2016). Plan nacional de demencias: antecedentes globales y síntesis de la estrategias chilena. Rev. Med. Clin. Condes 27, 286-296. doi: 10.1016/j.rmclc.2016.06.003

Garcia-Subirats, I., Vargas, I., Mogollón-Pérez, A. S., De Paepe, P., da Silva, M. R., Unger, J. P., et al. (2014). Barriers in access to healthcare in countries with different health systems. A cross-sectional study in municipalities of central Colombia and north-eastern Brazil. Soc. Sci. Med. 106, 204-213. doi: 10.1016/j. socscimed.2014.01.054

Georges, J., Jansen, S., Jackson, J., Meyrieux, A., Sadowska, A., and Selmes, M. (2008). Alzheimer's disease in real life-the dementia carer's survey. Int J. Geriatr. Psychiatry 23, 546-551. doi: 10.1002/gps.1984

Gilberti, N., Turla, M., Alberici, A., Bertasi, V., Civelli, P., Archetti, S., et al. (2012) Prevalence of frontotemporal lobar degeneration in an isolated population: the Vallecamonica study. Neurol. Sci. 33, 899-904. doi: 10.1007/s10072-011-0865-0 
Glassman, A., Gaziano, T. A., Bouillon Buendia, C. P., and Guanais de Aguiar, F. C. (2010). Confronting the chronic disease burden in Latin America and the Caribbean. Health Aff. 29, 2142-2148. doi: 10.1377/hlthaff. 2010.1038

González, F., Massad, C., Lavanderos, F., Albala, C., Sanchez, H., Fuentes, A., et al. (2009). Estudio Nacional de la Dependencia en las Personas Mayores. Chile: SENAMA.

Grinberg, L. T., Ferretti, R. E., Farfel, J. M., Leite, R., Pasqualucci, C. A., Rosemberg, S., et al. (2007). Brain bank of the Brazilian aging brain study group - a milestone reached and more than 1,600 collected brains. Cell Tissue Bank 8, 151-162. doi: 10.1007/s10561-006-9022-z

Gutiérrez-Robledo, L., and Arrieta-Cruz, I. (2015). Demencias en México: la necesidad de un Plan de Acció. Gac. Med. Mex. 151, 667-673. Available online at: http://www.medigraphic.com/pdfs/gaceta/gm-2015/gm155p.pdf

Helzner, E. P., Scarmeas, N., Cosentino, S., Tang, M. X., Schupf, N., and Stern, Y. (2008). Survival in Alzheimer disease: a multiethnic, population-based study of incident cases. Neurology 71, 1489-1495. doi: 10.1212/01.wnl.0000334278. 11022.42

Herrera, E. Jr., Caramelli, P., Silveira, A. S., and Nitrini, R. (2002). Epidemiologic survey of dementia in a community-dwelling Brazilian population. Alzheimer Dis. Assoc. Disord. 16, 103-108. doi: 10.1097/00002093-200204000-00007

Hojman, D., Duarte, F., Ruiz-Tagle, J., Troncoso, P., Budnich, M., and Slachevsky, A. (2017). The cost of dementia in an unequal country: the case of Chile. PLoS One 12:e0172204. doi: 10.1371/journal.pone.0172204

Ientile, L., De Pasquale, R., Monacelli, F., Odetti, P., Traverso, N., Cammarata, S., et al. (2013). Survival rate in patients affected by dementia followed by memory clinics (UVA) in Italy. J. Alzheimers Dis. 36, 303-309. doi: 10.3233/JAD130002

Kua, E. H., Ho, E., Tan, H. H., Tsoi, C., Thng, C., and Mahendran, R. (2014). The natural history of dementia. Psychogeriatrics 14, 196-201. doi: 10.1111/psyg. 12053

Lang, L., Clifford, A., Wei, L., Zhang, D., Leung, D., Augustine, G., et al. (2017). Prevalence and determinants of undetected dementia in the community: a systematic literature review and a meta-analysis. BMJ Open 7:e011146. doi: 10.1136/bmjopen-2016-011146

Le Couteur, D. G., Doust, J., Creasey, H., and Brayne, C. (2013). Political drive to screen for pre-dementia: not evidence based and ignores the harms of diagnosis. BMJ 347:f5125. doi: 10.1136/bmj.f5125

Liu, Z. (2013). Economic Costs of Dementia in Low and Middle Income Countries. PhD. Doctor of Philosophy, King's College, London.

Lobo, A., Launer, L. J., Fratiglioni, L., Andersen, K., Di Carlo, A., Breteler, M. M., et al. (2000). Prevalence of dementia and major subtypes in Europe: a collaborative study of population-based cohorts. Neurologic Diseases in the Elderly Research Group. Neurology 54, S4-S9.

Lopes, M. (2006). Estudo Epidemiológico de Prevalência de Demência em Ribeirão Preto; Epidemiological Survey of Prevalence of Dementia in Ribeirão Preto. $\mathrm{PhD}$ thesis, Faculdade de Medicina, Universidade de Paulo, São Paulo. doi: 10.11606/T.5.2006.tde-18042007-110300

Lopes, M. A., Hototian, S. R., Reis, G. C., Elkis, H., and Bottino, M. C. (2007). Systematic review of dementia prevalence 1994 to 2000. Dement. Neuropsychol. 1, 230-240. doi: 10.1590/s1980-57642008dn10300003

Lozano, R., Naghavi, M., Foreman, K., Lim, S., Shibuya, K., Aboyans, V., et al. (2012). Global and regional mortality from 235 causes of death for 20 age groups in 1990 and 2010: a systematic analysis for the Global Burden of Disease Study 2010. Lancet 380, 2095-2128. doi: 10.1016/S0140-6736(12) 61728-0

Llibre, J. J., Guerra, M. A., Pérez-Cruz, H., Bayarre, H., Fernández-Ramírez, S., González-Rodríguez, M., et al. (1999). Dementia syndrome and risk factors in adults older than 60 years old residing in Habana. Rev. Neurol. 29, 908-911.

Maestre, G. E. (2012). Assessing dementia in resource-poor regions. Curr. Neurol. Neurosci. Rep. 12, 511-519. doi: 10.1007/s11910-012-0300-9

Maestre, G. E., Pino-Ramírez, G., Molero, A. E., Silva, E. R., Zambrano, R., Falque, L., et al. (2002). The maracaibo aging study: population and methodological issues. Neuroepidemiology 21, 194-201. doi: $10.1159 / 000059524$

Manes, F. (2016). The huge burden of dementia in Latin America. Lancet Neurol. 15:29. doi: 10.1016/s1474-4422(15)00360-9
Manly, J., Schupf, N., Tang, M., Weiss, C., and Stern, Y. (2007). "Literacy and cognitive decline among ethnically diverse elder," in Cognitive Reserve: Theory and Applications, ed. Y. Stern (New York, NY: Taylor \& Francis), 219-235.

Marmot, M. (2005). Social determinants of health inequalities. Lancet 365, 1099-1104. doi: 10.1016/S0140-6736(05)71146-6

Meng, X., and D'arcy, C. (2012). Education and dementia in the context of the cognitive reserve hypothesis: a systematic review with meta-analyses and qualitative analyses. PLoS One 7:e38268. doi: 10.1371/journal.pone. 0038268

Ministerio de Salud, G. D. C. (2015). Documento Preliminar Para la Elaboración del Plan Nacional Para las Demencias. Argentina: Ministerio de Salud.

Mitchell, S. L., Teno, J. M., Kiely, D. K., Shaffer, M. L., Jones, R. N., Prigerson, H. G., et al. (2009). The clinical course of advanced dementia. N. Engl. J. Med. 361, 1529-1538. doi: 10.1056/NEJMoa0902234

Murray, C. J., Vos, T., Lozano, R., Naghavi, M., Flaxman, A. D., Michaud, C., et al. (2012). Disability-adjusted life years (DALYs) for 291 diseases and injuries in 21 regions, 1990-2010: a systematic analysis for the Global Burden of Disease Study 2010. Lancet 380, 2197-2223. doi: 10.1016/S0140-6736(12)61689-4

Nitrini, R., Bottino, C. M., Albala, C., Custodio Capuñay, N. S., Ketzoian, C., Llibre Rodriguez, J. J., et al. (2009). Prevalence of dementia in Latin America: a collaborative study of population-based cohorts. Int. Psychogeriatr. 21, 622-630. doi: 10.1017/S1041610209009430

Nitrini, R., Caramelli, P., Herrera, E. Jr., Bahia, V. S., Caixeta, L. F., Radanovic, M., et al. (2004). Incidence of dementia in a community-dwelling Brazilian population. Alzheimer Dis. Assoc. Disord. 18, 241-246.

Nitrini, R., Caramelli, P., Herrera, E. Jr., de Castro, I., Bahia, V. S., Anghinah, R., et al. (2005). Mortality from dementia in a community-dwelling Brazilian population. Int. J. Geriatr. Psychiatry 20, 247-253. doi: 10.1002/gps.1274

Olavarría, L., Mardones, C., Delgado, C., and Slachevsky Ch, A. (2016). Chilean health professionals perception of knowledge about dementia. Rev. Med. Chil. 144, 1365-1368. doi: 10.4067/S0034-98872016001000019

O’Neill, S., Richly, P., Prats, M., Mastadueno, R., Pontello, N., Christie, C., et al. (2013). Diagnosis and management of cognitive disorders in Latin America: new technologies or more knowledge needed? Alzheimers Dement. 9:P645. doi: 10.1016/j.jalz.2013.05.1315

PAMI. (2016). Plan Estratégico Nacional Pami para un Cerebro Saludable, Enfermedad De Alzheimer Y Otras Demencias 2016-2019. (Buenos Aires: PAMI.

Parra, M. A. (2014). Overcoming barriers in cognitive assessment of Alzheimer's disease. Dement. Neuropsychol. 8, 95-98. doi: 10.1590/s1980$57642014 \mathrm{dn} 82000002$

Prince, M., Ali, G. C., Guerchet, M., Prina, A. M., Albanese, E., and Wu, Y. T. (2016). Recent global trends in the prevalence and incidence of dementia, and survival with dementia. Alzheimers Res. Ther. 8:23. doi: 10.1186/s13195-0160188-8

Prince, M., Bryce, R., Albanese, E., Wimo, A., Ribeiro, W., and Ferri, C. P. (2013). The global prevalence of dementia: a systematic review and metaanalysis. Alzheimers Dement. 9, 63.e2-75.e2. doi: 10.1016/j.jalz.2012.11.007

Prince, M., Bryce, R., and Ferri, C. (2011). Alzheimer's Disease International-World Alzheimer Report 2011: The Benefits of Early Diagnosis and Intervention. London: Alzheimer's Disease International.

Prince, M., Wimo, A. M. G., Gemma-Claire, A., Yu-Tzu, W., and Prina, M. (2015). World Alzheimer Report 2015 The Global Impact of Dementia An Analysis of Prevalence, Incidence, Cost and trends. London: Alzheimer's Disease International (ADI).

Qiu, C., Backman, L., Winblad, B., Aguero-Torres, H., and Fratiglioni, L. (2001). The influence of education on clinically diagnosed dementia incidence and mortality data from the Kungsholmen Project. Arch. Neurol. 58, 2034-2039. doi: 10.1001/archneur.58.12.2034

Ramos-Cerqueira, A., Torres, A., Crepaldi, A., Oliveira, N., Scazufca, M., Menezes, P., et al. (2005). Identification of dementia cases in the community: a Brazilian experience. J. Am. Geriatr. Soc. 53, 1738-1742. doi: 10.1111/j.15325415.2005.53553.x

Romero, S., and Ge, M. (2007). Knowledge, belief and report of the practice of general practicioners in primary attention in Maracaibo, Venezuela about dementia. Invest. Salud 9, 10-15.

Rosso, S. M., Donker Kaat, L., Baks, T., Joosse, M., de Koning, I., Pijnenburg, Y., et al. (2003). Frontotemporal dementia in The Netherlands: patient 
characteristics and prevalence estimates from a population-based study. Brain 126, 2016-2022. doi: 10.1093/brain/awg204

Russ, T. C., Murianni, L., Icaza, G., Slachevsky, A., and Starr, J. M. (2016). Geographical variation in dementia mortality in Italy, New Zealand, and Chile: evidence for an effect of lattitude and possible vitamin D. Dement. Geriatr. Cogn. Disord. 42, 31-41. doi: 10.1159/000447449

Satizabal, C. L., Beiser, A. S., Chouraki, V., Chêne, G., Dufouil, C., and Seshadri, S. (2016). Incidence of dementia over three decades in the framingham heart study. N. Engl. J. Med. 374, 523-532. doi: 10.1056/NEJMoa 1504327

Sharp, E. S., and Gatz, M. (2011). Relationship between education and dementia: an updated systematic review. Alzheimer Dis. Assoc. Disord. 25, 289-304. doi: 10.1097/WAD.0b013e318211c83c

Slachevsky, A., Abusleme Lama, M., and Arenas Massa, A. (2016). Cuidados paliativos en personas con demencia severa: reflexiones y desafios. Palliative care of patients with severe dementia. Rev. Med. Chil. 144, 94-101. doi: $10.4067 / \mathrm{s} 0034-98872016000100012$

Slachevsky, A., Budinich, M., Miranda-Castillo, C., Núñez-Huasaf, J., Silva, J. R., Muñoz-Neira, C., et al. (2013). The CUIDEME Study: determinants of burden in chilean primary caregivers of patients with dementia. J. Alzheimers Dis. 35, 297-306. doi: 10.3233/JAD-122086

Slachevsky, A., and Gajardo, J. (in press). "Dementia care in Chile: making dementia an urgent matter for public health," in Dementia Care: International Perspectives, eds A. Burns and P. Robertt (London: MHS IDEAL book).

Sorensen, S., Duberstein, P., Gill, D., and Pinquart, M. (2006). Dementia care: mental health effects, intervention strategies, and clinical implications. Lancet Neurol. 5, 961-973. doi: 10.1016/s1474-4422(06) 70599-3

Sousa, R. M., Ferri, C. P., Acosta, D., Guerra, M., Huang, Y., Jacob, K., et al. (2010). The contribution of chronic diseases to the prevalence of dependence among older people in Latin America, China and India: a 10/66 Dementia Research Group population-based survey. BMC Geriatr. 10:53. doi: 10.1186/1471-231810-53

Stern, Y. (2009). Cognitive reserve. Neuropsychologia 47, 2015-2028. doi: 10.1016/j.neuropsychologia.2009.03.004

Stern, Y. (2012). Cognitive reserve in ageing and Alzheimer's disease. Lancet Neurol. 11, 1006-1012. doi: 10.1016/s1474-4422(12)70191-6

Truzzi, A., Valente, L., Ulstein, I., Engelhardt, E., Laks, J., and Engedal, K. (2012). Burnout in familial caregivers of patients with dementia. Rev. Bras. Psiquiatr. 34, 405-412. doi: 10.1016/j.rbp.2012.02.006

Turtós Carbonell, L. B., Rodríguez Rosa, Y., Rodríguez Abreu, Y., and Martínez, E. O. (2016). Caracterización demográfica de cuidadores informales de ancianos con ictus y demencias en Santiago de Cuba. Rev. Encuentros 14, 61-72. doi: 10.15665/re.v14i2.795
United Nations. (2015). World Population Prospects: The 2015 Revision, Key Findings and Advance Tables. Working Paper No. ESA/P/WP.241.World Population Prospects. New York, NY: United Nations.

Veras, P., Caldas, C., Dantas, S., Sancho, L., Sicsú, B., and Motta, L. (2008). Demented elderly people living at home in Rio de Janeiro, Brazil: evaluation of expenditure care. Psychogeriatrics 8, 88-95. doi: 10.1111/j.1479-8301.2008. 00237.x

Wang, H. X., Gustafson, D. R., Kivipelto, M., Pedersen, N. L., Skoog, I., Windblad, B., et al. (2012). Education halves the risk of dementia due to apolipoprotein epsilon4 allele: a collaborative study from the Swedish brain power initiative. Neurobiol. Aging 33, 1007.e1-1007.e7. doi: 10.1016/j. neurobiolaging.2011.10.003

WHO. (2015). World Report on Ageing And Health. Washington, DC: World Health Organization's (WHO).

Wimo, A., Guerchet, M., Ali, G. C., Wu, Y. T., Prina, A. M., Winblad, B., et al. (2017). The worldwide costs of dementia 2015 and comparisons with 2010. Alzheimers Dement. 13, 1-7. doi: 10.1016/j.jalz. 2016.07.150

Wimo, A., Winblad, B., and Jönsson, L. (2010). The worldwide societal costs of dementia: estimates for 2009. Alzheimers Dement. 6, 98-103. doi: 10.1016/j.jalz. 2010.01.010

Winblad, B., Amouyel, P., Andrieu, S., Ballard, C., Brayne, C., Brodaty, H., et al. (2016). Defeating Alzheimer's disease and other dementias: a priority for European science and society. Lancet Neurol. 15, 455-532. doi: 10.1016/S14744422(16)00062-4

World Health Organization, and Alzheimer's Disease International. (2012). Dementia: A Public Health Priority. Geneva: World Health Organization (WHO).

Wu, Y. T., Beiser, A. S., Breteler, M. M. B., Fratiglioni, L., Helmer, C., Hendrie, H. C., et al. (2017). The changing prevalence and incidence of dementia over time-current evidence. Nat. Rev. Neurol. 13, 327-339. doi: $10.1038 /$ nrneurol.2017.63

Conflict of Interest Statement: The authors declare that the research was conducted in the absence of any commercial or financial relationships that could be construed as a potential conflict of interest.

Copyright (c) 2017 Custodio, Wheelock, Thumala and Slachevsky. This is an open-access article distributed under the terms of the Creative Commons Attribution License (CC BY). The use, distribution or reproduction in other forums is permitted, provided the original author(s) or licensor are credited and that the original publication in this journal is cited, in accordance with accepted academic practice. No use, distribution or reproduction is permitted which does not comply with these terms. 